\title{
PERANCANGAN SISTEM INFORMASI KEPENDUDUKAN DI PERUMAHAN CITRA SWARNA RIVERSIDE
}

\author{
Agung Pujiyanto ${ }^{1}$, Nur Alamsyah ${ }^{2}$ \\ 1,2,3 Universitas Indraprasta PGRI \\ Jl. Raya Tengah No. 80, Kel Gedong, Kec. Pasar Rebo, Jakarta Timur 13760, Jakarta \\ agungpujiyanto1322@gmail.com, alamcbr11@gmail.com
}

\begin{abstract}
ABSTRAK
Penulis melakukan riset tentang sistem informasi di Perumahan Citra Swarna Riverside khususnya ke bagian administrasi kependudukan dan menemukan bahwa admin masih melakukan pendataan penduduk dengan cara manual serta menggunakan aplikasi Microsoft Excel sebagai program aplikasi untuk membantu menyimpan dan menghitung data, sehingga masih memiliki beberapa kelemahan, salah satunya adalah proses penyimpanan data yang terbatas sehingga banyak data yang tercampur dan sulit untuk dicari. Tujuan dari penelitian adalah untuk memudahkan bagian kependudukan dalam melakukan pendataan penduduk, dan yang berkaitan dengan kependudukan serta mempermudah proses administrasi kependudukan. Metode penelitian yang digunakan dalam perancangan sistem informasi kependudukan di Perumahan Citra Swarna Riverside ini adalah metode kualitatif dengan metode pengambilan data studi lapangan, yaitu melalui pengamatan langsung, wawancara dengan pihak terkait, dan melakukan dokumentasi untuk mendapatkan informasi yang dibutuhkan. Dalam membangun sistem ini, digunakan alat bantu perancangan sistem yaitu Unified Modelling Language (UML). Dapat disimpulkan, sistem kependudukan ini dapat mempermudah pekerjaan bagian administrasi kependudukan di Perumahan Citra Swarna Riverside.
\end{abstract}

Kata Kunci: Sistem, Informasi, Administrasi, Kependudukan.

\begin{abstract}
The author conducted research on information systems at Citra Swarna Riverside Housing, especially to the population administration section and found that the admin still carried out population data collection manually and used the Microsoft Excel application as an application program to help store and calculate data, so it still has several weaknesses, one of which is is a limited data storage process so that a lot of data is mixed and difficult to find. The purpose of the research is to facilitate the population department in conducting population data collection, and those related to population and to facilitate the population administration process. The research method used in the design of the population information system at Citra Swarna Riverside Housing is a qualitative method with field study data collection methods, namely through direct observation, interviews with related parties, and conducting documentation to obtain the required information. In building this system, a system design tool is used, namely the Unified Modeling Language (UML). It can be concluded, this population system can facilitate the work of the population administration department at Citra Swarna Riverside Housing.
\end{abstract}

Key Word: System, Information, Administration, Population.

\section{PENDAHULUAN}

Perkembangan teknologi informasi yang terjadi di era saat ini mempermudah pengguna untuk menggunakan teknologi informasi dalam menyelesaikan pekerjaannya. Banyak organisasi dan instansi, baik pemerintah maupun badan usaha, memanfaatkan perkembangan teknologi informasi. Penggunaan komputer dalam penanganan dan pengolahan data memerlukan suatu prosedur yang tepat, dalam hal ini adalah perangkat lunak aplikasi atau disebut juga program. Pengolahan data yang tepat dan cepat mampu meningkatkan kinerja (Yusuf et al., 2021).
Aplikasi berbasis desktop berguna untuk memberikan kemudahan bagi pengguna komputer atau laptop dalam mengelola data sehingga mampu menghasilkan sebuah laporan yang cepat, tepat, dan akurat. Meskipun saat ini banyak pengguna sudah mulai beralih ke aplikasi berbasis smartphone, baik itu Android maupun iOS, penggunaan aplikasi berbasis desktop masih efektif untuk digunakan. Hal tersebut disebabkan oleh keterbatasan perangkat yang mendukung aplikasi berbasis Android ataupun iOS untuk mencetak laporan (Kurniawan \& Syahputra, 2018). 
Setiap perusahaan, baik swasta maupun instansi pemerintah, tidak akan pernah bisa terlepas dari suatu kegiatan yang disebut dengan meeting atau rapat. Kegiatan ini dilakukan untuk membicarakan hal-hal penting dalam pengambilan keputusan (Maulana et al., 2021).

Perumahan Citra Swarna Riverside merupakan sebuah komplek hunian yang mulai di bangun pada tahun 2017 dan mulai dihuni pada tahun 2019. Terletak di Ds. Bojong Kecamatan Klapanunggal Kabupaten Bogor. Perumahan Citra Swarna Riverside masuk dalam kategori rumah bersubsidi. Perumahan Citra Swarna Riverside memberikan pelayanan terbaiknya salah satunya perihal kependudukan. Dan di harapkan supaya warga nyaman dan betah bertempat tinggal di Perumahan Citra Swarna Riverside.

Dalam kegiatan pendataan penduduk, Perumahan Citra Swarna Riverside belum mempunyai sebuah aplikasi yang dapat mendukung sistem kependudukan. Dalam proses pendataan penduduk, bagian Administrasi masih menggunakan sistem manual. Staf harus menyimpan semua data secara manual dengan menggunakan program Microsoft office di setiap kegiatannya. Oleh karena itu, banyak laporan tumpang tindih dan proses pendataan penduduk tidak terintegrasi dengan sistem kependudukan. Proses pengolahan data yang belum optimal tersebut perlu dibenahi dengan sistem baru yang terkomputerisasi dan terintegrasi dengan baik agar pengolahan data menjadi lebih efektif dan efisien.

Tujuan dari penelitian ini adalah merancang sistem informasi kependudukan untuk memudahkan bagian administrasi dalam melakukan pendataan serta mempermudah proses laporannya.

perancangan adalah proses pengembangan spesifikasi baru berdasarkan rekomendasi hasil analisis sistem (Subhan, 2012). Sistem adalah sekelompok unsur yang erat hubungannya satu dengan yang lain, berfungsi bersama-sama untuk mencapai tujuan tertentu (Sutabri, 2012).

Aplikasi merupakan penerapan, menyimpan sesuatu hal, data, permasalahan, pekerjaan kedalam suatu sarana atau media yang dapat digunakan untuk diterapkan menjadi sebuah bentuk yang baru (Hartono, 2014).

Berdasarkan penjelasan di atas, dirancanglah sistem informasi kependudukan di Perumahan Citra Swarna Riverside. Dengan menggunakan sistem aplikasi ini, proses kependudukan dan pembuatan laporan akan menjadi lebih efektif dan efisien.

Hal ini sesuai dengan hasil penelitian yang menyimpulkan bahwa dengan adanya sistem aplikasi berbasis desktop, pembuatan laporan akan menjadi lebih efektif dan efisien, serta dapat mempermudah bagian administrasi dalam melakukan tugasnya (Ismunandar et al., 2021).

\section{METODE PENELITIAN}

Metode penelitian yang digunakan oleh penulis adalah metode penelitian kualitatif. Metode penelitian kualitatif adalah pengumpulan data pada suatu latar alamiah dengan maksud menafsirkan fenomena yang terjadi dimana peneliti adalah sebagai instrumen kunci (Anggito \& Setiawan, 2018).

Rancangan kegiatan penelitian dimulai pada bulan April 2021 dengan kunjungan langsung ke lapangan untuk mencatat hal-hal penting mengenai suatu masalah, lalu melakukan wawancara langsung dengan pihak yang bersangkutan yaitu staf administrasi di Perumahan Citra Swarna Riverside.

Dalam membangun sistem aplikasi ini, digunakan alat bantu perancangan sistem yaitu Unified Modelling Language (UML).

Unified Modelling Language (UML) merupakan bahasa visual untuk pemodelan dan komunikasi mengenai sebuah sistem dengan menggunakan diagram dan teks-teks pendukung (Rosa \& Shalahuddin, 2015).

Bahasa pemrograman yang penulis gunakan adalah java dan database yang digunakan adalah MySQL.

Bahasa Pemrograman Java merupakan salah satu dari sekian banyak bahasa pemograman yang dapat dijalankan di berbagai sistem operasi termasuk telepon genggam (Nofriadi, 2015). 
MySQL adalah software yang termasuk dalam sistem manajemen basis data SQL (Database Management System) atau dikenal juga dengan DBMS yang multithread dan multi-user (Yudhanto \& Purbayu, 2014).

\section{HASIL DAN PEMBAHASAN}

Analisa Permasalahan

Berdasarkan hasil pengamatan, peneliti mengidentifikasi permasalahan yang ada di tempat penelitian adalah sebagai berikut.

1. Perumahan Citra Swarna Riverside merupakan sebuah komplek hunian dimana banyak sekali kepala keluarga yang belum terdata. Dengan adanya aplikasi maka pendataan penduduk akan semakin lebih mudah.

2. Akan tetapi, warga di Perumahan Citra Swarna Riverside masih Belum begitu maksimal dalam mengolah masalah tersebut dikarenakan tingkat pengetahuan akan teknologi masih minim. Keterbatasan informasi juga menjadi penghambat dalam pengembangan bisnis di dunia perdagangan.

\section{Alternatif Penyelesaian Masalah}

Dari hasil analisa masalah di atas dapat diangkat penyelesaian masalah dengan pembuatan aplikasi Pendataan Penduduk Berbasis Java pada Perumahan Citra Swarna Riverside beserta implementasi programmnya. Harus dipastikan bahwa aplikasi layanan ini dapat berjalan dengan baik. Disamping itu, juga perlu dipastikan tentang orang yang akan mengoperasikan, mengontrol dan memelihara sistem tersebut.

\section{Use Case Diagram yang Diusulkan}

Berikut Use Case Diagram terhadap sistem informasi kependudukan yang diusulkan yaitu:

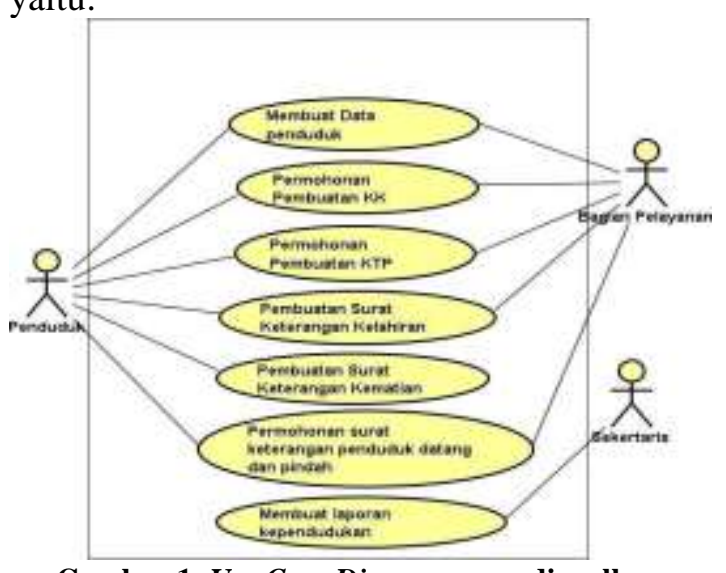

Gambar 1. Use Case Diagram yang diusulkan

\section{Class Diagram Yang Diusulkan}

Berikut Class Diagram terhadap sistem informasi kependudukan yang diusulkan yang diusulkan yaitu:

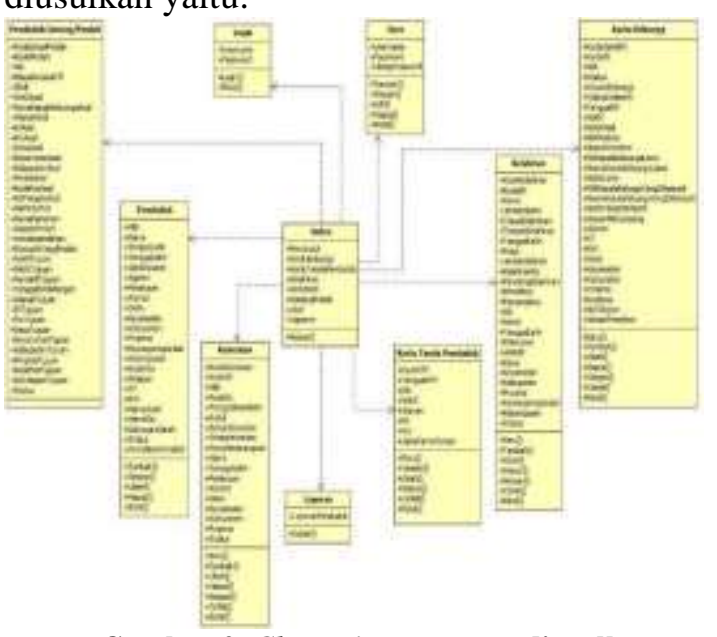

Gambar 2. Class Diagram yang diusulkan

\section{Tampilan Halaman Login}

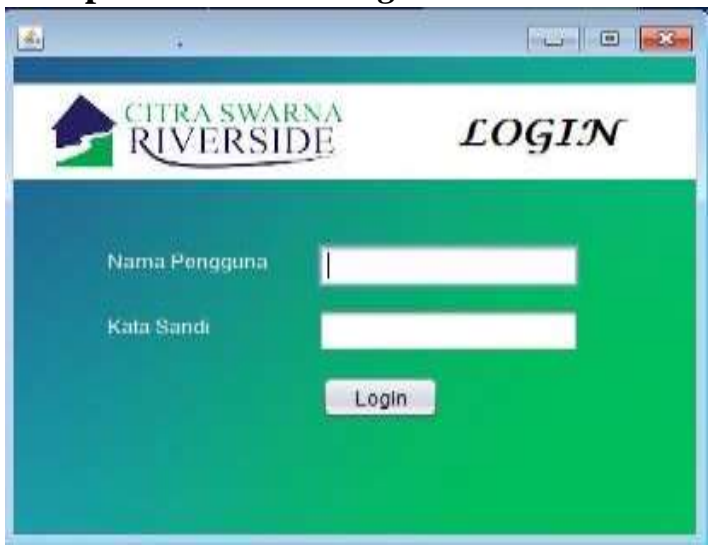

Gambar 3. Tampilan Halaman Login

Pada tampilan awal menjalankan aplikasi ini menampilkan form login. Pengguna diharuskan memasukkan username dan password agar dapat masuk ke halaman menu utama.

\section{Tampilan Menu Utama}

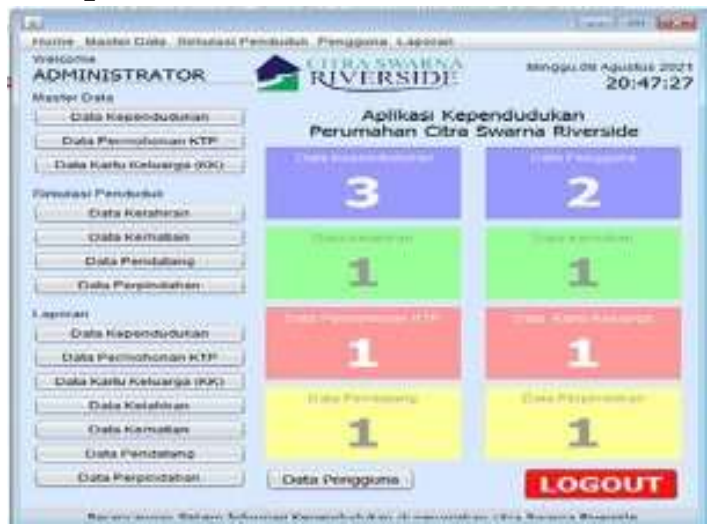

Gambar 4. Tampilan Menu Utama

1191 | Perancangan Sistem Informasi Kepedudukan di Perumahan Citra Swarna Riverside 
Pada tampilan ini menampilkan menu utama sekaligus form data kependudukan, kartu keluarga, kartu tanda penduduk, kematian, kelahiran, perpindahan, kepindahan dan laporam - laporannya.

\section{Tampilan Menu Data Kependudukan}

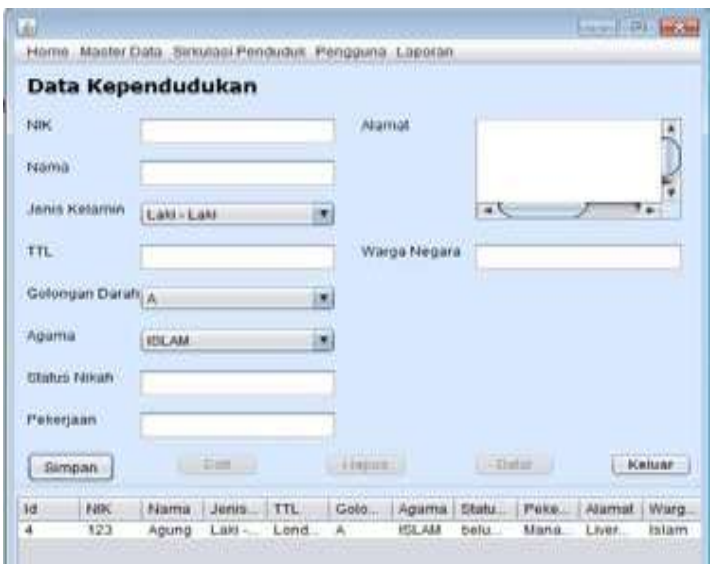

Gambar 5. Tampilan Menu Data Penduduk

Halaman ini merupakan form input data penduduk untuk menyimpan data penduduk ke dalam database. Berikut merupakan tampilan dari desain Kependudukan.

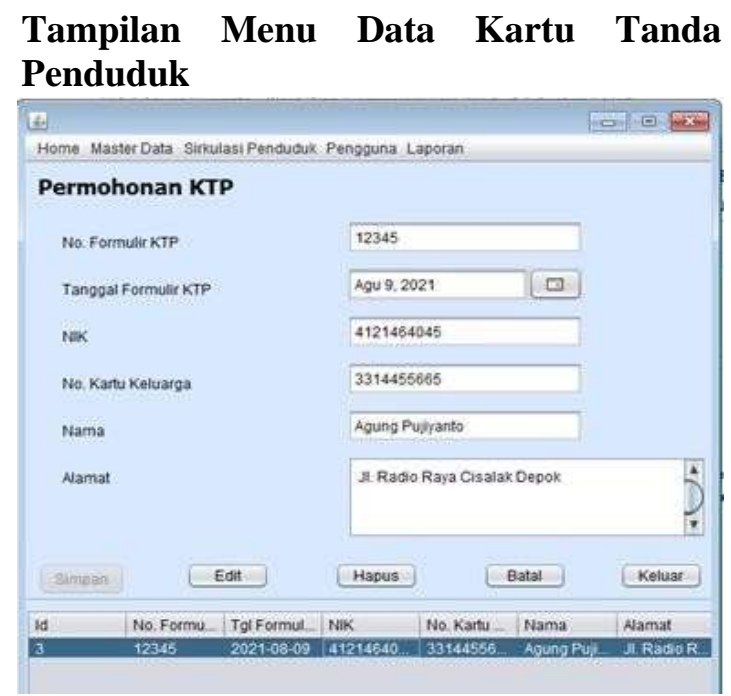

Gambar 6. Tampilan Menu Data KTP

Halaman ini merupakan form input permohonan KTP untuk warga yang memerlukan surat pengantar untuk mengajukan pembuatan KTP ke kecamatan. Berikut merupakan rancangan dari halaman tersebut

\section{Tampilan Menu Data Kartu Keluarga}

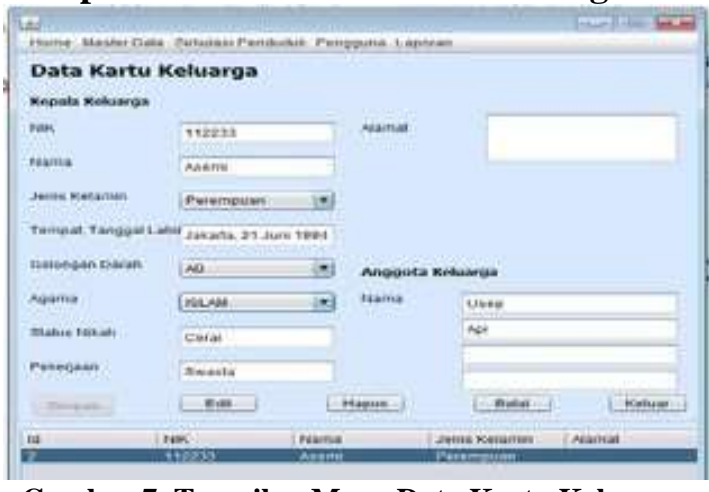

Gambar 7. Tampilan Menu Data Kartu Keluarga

Halaman ini merupakan form input permohonan KK untuk warga yang memerlukan surat pengantar untuk mengajukan pembuatan KK ke kecamatan. Berikut merupakan rancangan dari halaman tersebut.

\section{Tampilan Menu Data Kelahiran}

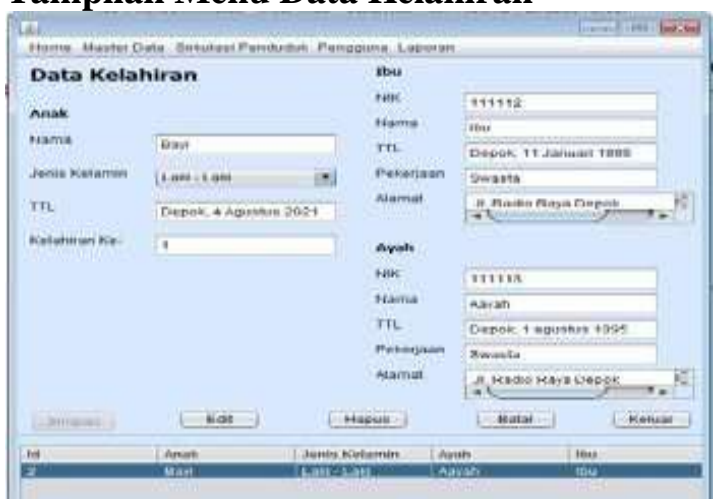

Gambar 8. Tampilan Menu Data Kelahiran

Halaman ini merupakan form input pembuatan Keterngan Kelahiran untuk warga sebagai pengantar dari kantor kepala desa untuk mengajukan pembuatan Akte Kelahiran ke Dinas Kependudukan.

\section{Tampilan Menu Data Kematian}

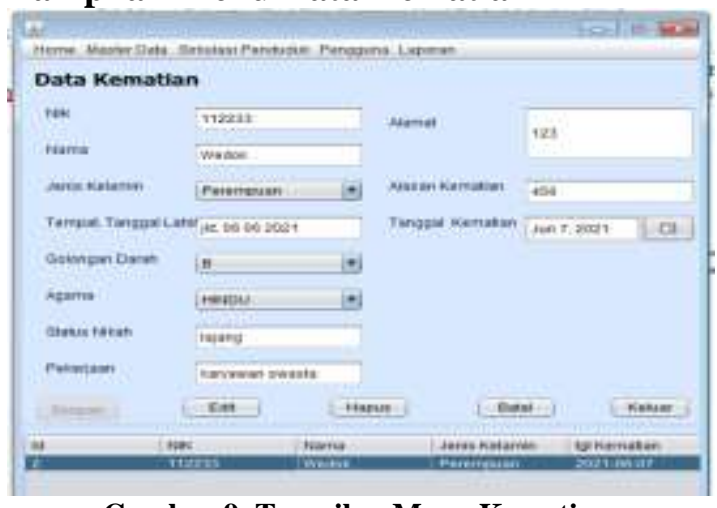

Gambar 9. Tampilan Menu Kematian 
Halaman ini merupakan form permohonan pembuatan surat keterangan kematian untuk warga yang sudah meninggal.

\section{Tampilan Menu Data Kedatangan}

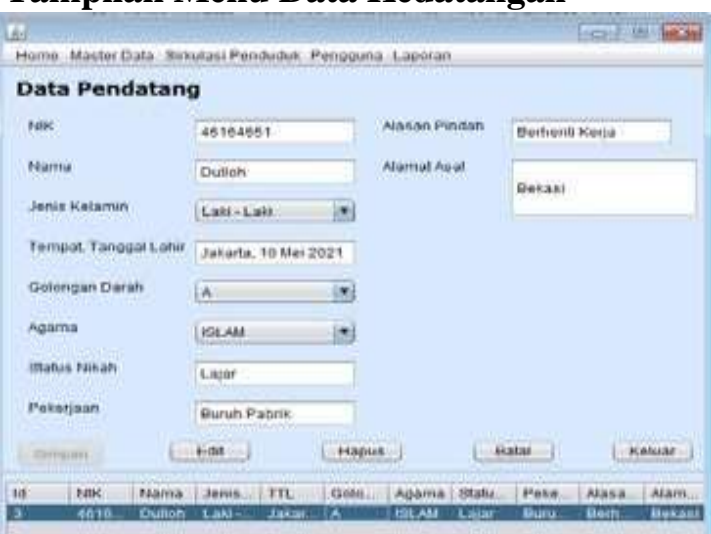

Gambar 10. Tampilan Menu Kedatangan

Halaman ini merupakan form permohonan pembuatan surat keterangan Datang untuk keperluan administrasi bagi warga pendatang.

\section{Tampilan Menu Data Perpindahan}

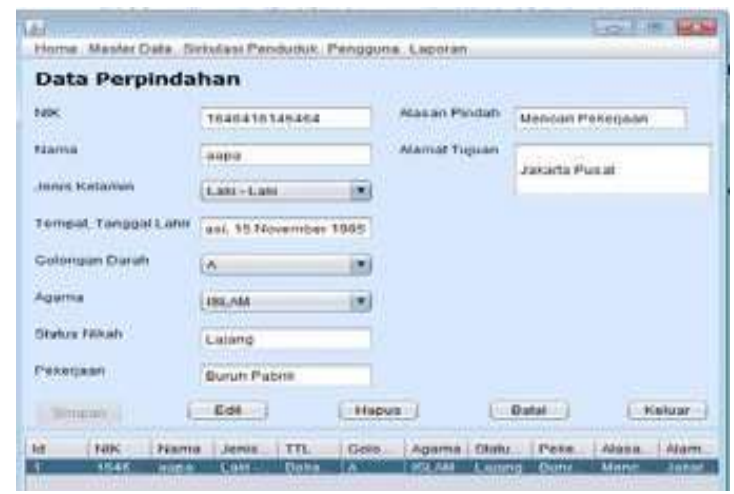

Gambar 11. Tampilan Menu Perpindahan

Halaman ini merupakan form permohonan pembuatan surat keterangan Pindah bagi warga yang akan pindah ke wilayahlain.

\section{Tampilan Laporan Kependudukan}

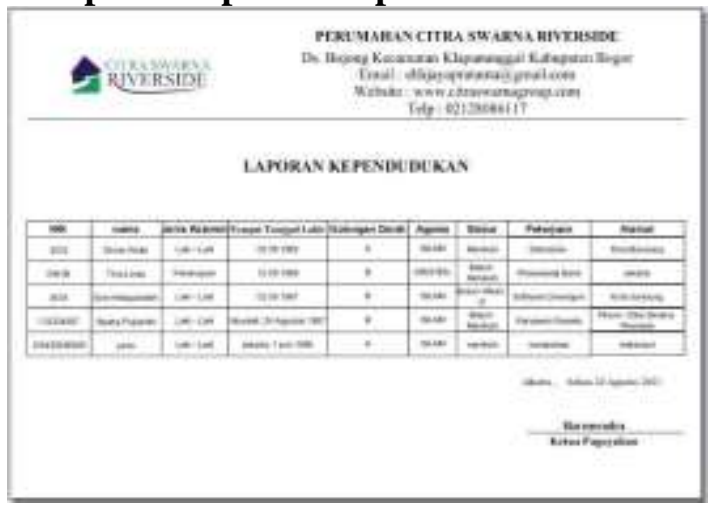

Gambar 12. Tampilan Laporan Kependudukan
Pada tampilan ini menampilkan sebuah data lengkap warga Perumahan Citra Swarna Riverside beserta alamatnya.

\section{Tampilan Laporan Data Kartu Tanda} Penduduk

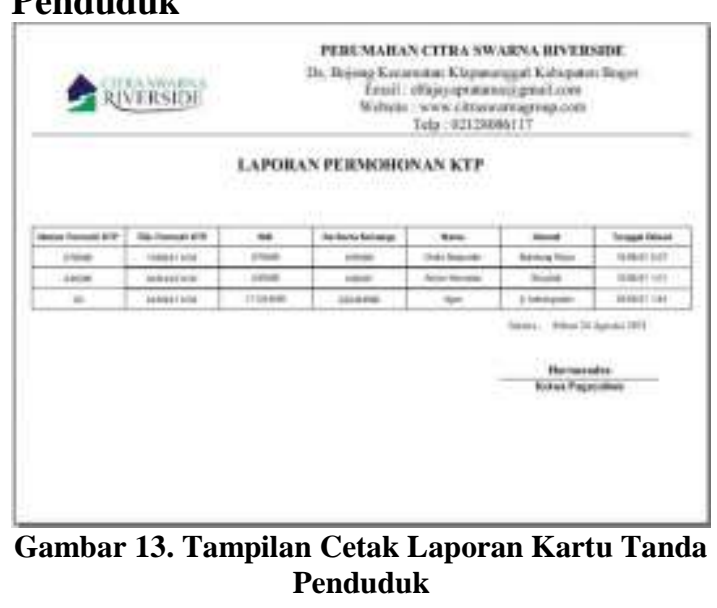

Pada tampilan ini menampilkan sebuah data warga yang ingin membuat Kartu Tanda Penduduk.

Tampilan Laporan Data Kartu Keluarga

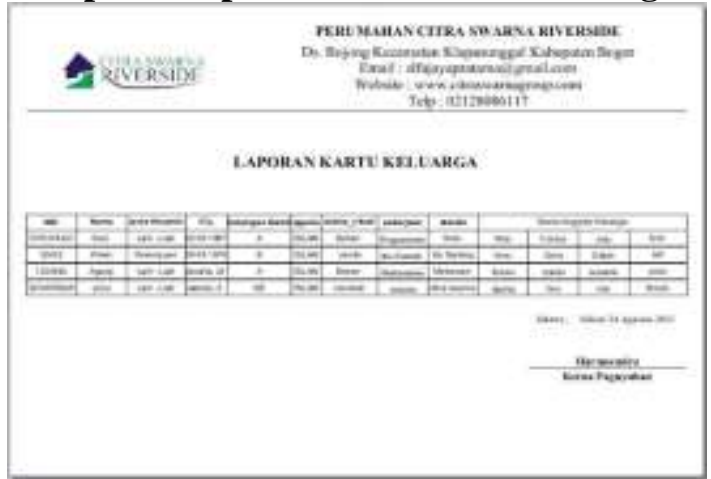

Gambar 14. Tampilan Laporan Kartu Keluarga

Pada tampilan ini menampilkan sebuah laporan data kartu keluarga berikut anggota keluarga yang bermukim di Perumahan Citra Swarna Riverside.

\section{Tampilan Laporan Kelahiran}

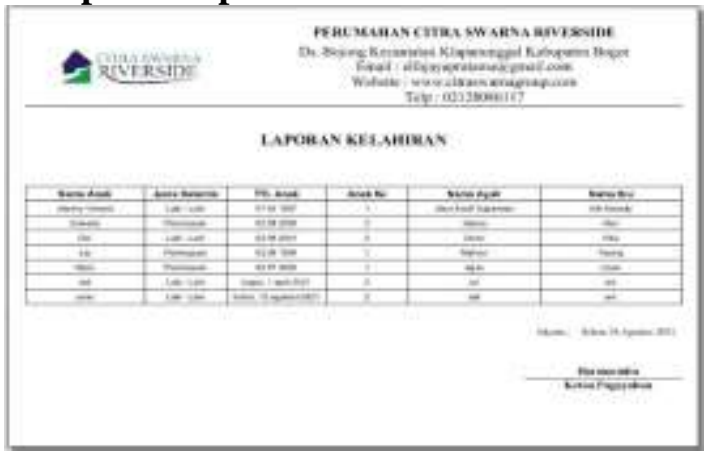

Gambar 15. Tampilan Laporan Kelahian

1193 | Perancangan Sistem Informasi Kepedudukan di Perumahan Citra Swarna Riverside 
Pada tampilan ini menampilkan sebuah laporan data lengkap kelahiran dengan orang tuanya.

\section{Tampilan Laporan Kematian}

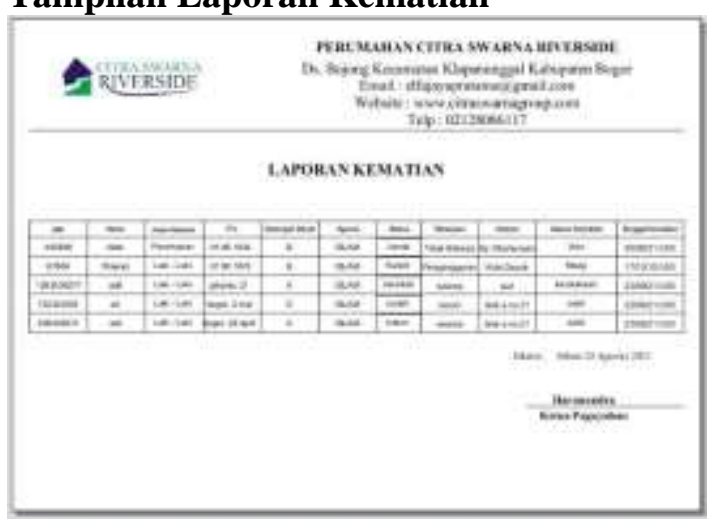

Gambar. 16. Tampilan Laporan Kematian

Pada tampilan ini menampilkan laporan data lengkap kematin warga yang meninggal.

\section{Tampilan Laporan Kedatangan}

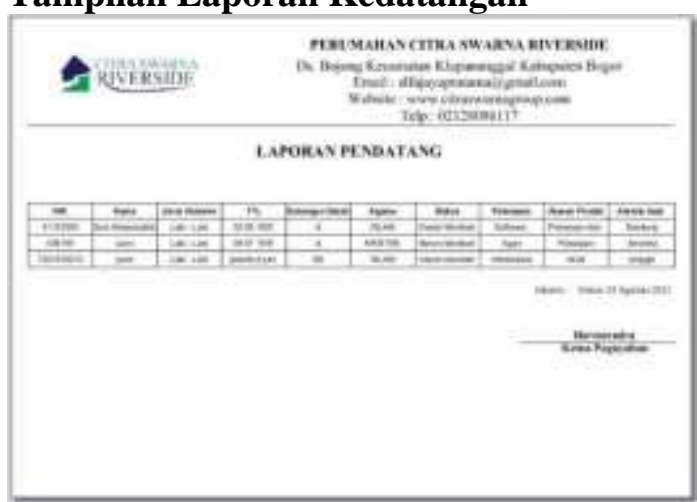

Gambar 17. Tampilan Laporan Kedatangan

Pada tampilan ini menampilkan data lengkap warga baru atau pendatang.

\section{Tampilan Laporan Perpindahan}

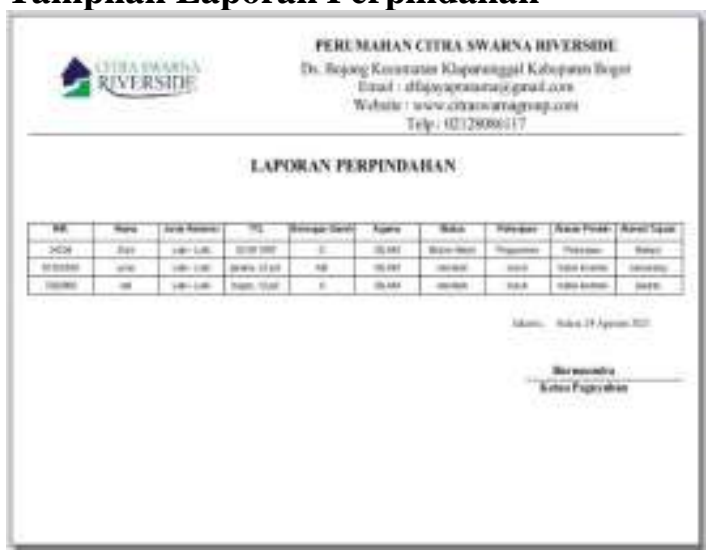

Gambar. 18. Tampilan Laporan Kedatangan
Pada tampilan ini menampilkan data lengkap warga yang ingin pindah dari Perumahan Citra Swarna Riverside.

\section{SIMPULAN DAN SARAN}

Peniliti memiliki simpulan sebagai berikut.

1. Membangun sistem kependudukan yang efektif, efisien dan user friendly.

2. Penulisan skripsi ini bertujuan untuk menghasilkan sebuah aplikasi sistem informasi kependudukan yang nantinya akan digunakan oleh pihak Perumahan Citra Swarna Riverside.

3. Membuat aplikasi sistem informasi penjualan menggunakan program java netbeans dan xampp.

4. Penerapan dan uji coba program sistem informasi kependudukan untuk membantu mengatasi masalah yang ada di Perumahan Citra Swarna Riverside.

Sejalan dengan sistem yang penulis buat, penulis mengemukakan saran bahwa sistem aplikasi ini masih harus ditingkatkan lagi, baik dari segi fitur maupun pemeliharaannya, agar dapat memenuhi kebutuhan administrsi kependudukan ke depannya serta tidak menghambat operasional.

1. Aplikasi pendukung ini supaya bisa dioptimalkan dengan melakukan pengembangan fitur-fitur yang dibutuhkan agar dapat mempermudah pengguna, seperti terintegrasi dengan sistem departemen lain.

2. Aplikasi pendukung ini agar bisa dikembangkan lagi dalam tampilan interface- nya supaya pengguna merasa lebih nyaman, mudah, dan cepat dalam menggunakannya.

3. Petugas-petugas yang telah ditunjuk perlu melakukan pengawasan secara berkala dalam proses pemeliharaan sistem komputer.

4. Backup data harus selalu dilakukan dalam suatu periode tertentu agar terhindar dari hal- hal yang tidak diinginkan yang bersifat merugikan.

\section{DAFTAR PUSTAKA}

Anggito, A., \& Setiawan, J. (2018). Metodologi Penelitian Kualitatif. $\mathrm{Cv}$ Jejak.

Hartono, J. (2014). Analisis Dan Desain Sistem Informasi. Andi Offset.

Ismunandar, A. R. N., Afrizal, T., \& 
Dwitiyanti, N. (2021). Aplikasi Penjualan Aksesoris Handphone Pada Asia Accessories Hp. Seminar Nasional Riset Dan Inovasi Teknologi (Semnas Ristek), 86-91.

Kurniawan, E., \& Syahputra, A. K. (2018). Perancangan Aplikasi Pemesanan Dan Pembayaran Berbasis Desktop Pada Percetakan Ud. Azka Gemilang Menggunakan Metode Prototype. Seminar Nasional Raya, 9986(September), 105-110.

Maulana, A., Septianzah, K., \& Hartuti, P. M. (2021). Sistem Pemesanan Meeting Room Di Pt. Saptaindra Sejati Menggunakan Teknologi Java Netbeans. Seminar Nasional Riset Dan Inovasi Teknologi (Semnas Ristek), 7378.

Rosa, A. S., \& Shalahuddin, M. (2015).
Rekayasa Perangkat Lunak. Penerbit Informatika.

Subhan, M. (2012). Analisa Perancangan Sistem. Lentera Ilmu Cendekia.

Sutabri, T. (2012). Konsep Sistem Informasi. Andi Offset.

Yudhanto, Y., \& Purbayu, A. (2014). Toko Online Dengan Php Dan My Sql. Elex Media Komputindo.

Yusuf, D., Afrizal, T., \& Budiarto, A. (2021). Perancangan Sistem Aplikasi Pemesanan Lapangan Futsal Berbasis Java Pada Wirabujana Futsal Indramayu. Journal of Information System, Applied, Management, Accounting And Research (Jisamar), 5(1), 125-131. Http://Journal.Stmikjayakarta.Ac.Id/Ind ex.Php/Jisamar/Article/View/347 